\title{
A thermal-optical analysis of a compound parabolic concentrator for single and multiphase flows, including superheat*
}

\author{
A. Y. El-Assay, Cairo, and J. A. Clark, Ann Arbor, Michigan, USA
}

\begin{abstract}
A thermal and optical analysis of the performance of a refrigerant charged Compound Parabolic Concentrator (CPC) for solar applications operating in non-boiling, boiling and superheated regimes is presented. The performance of the CPC working under these single and multiphase conditions is governed by the axial fractional channel lengths of the non-boiling and the superheating regions. The overall thermal loss coefficient, the dimensionless capacitance rate and collector efficiency factors for various CPC operating regions are defined. A new "Generalized Heat Removal Factor", $\mathscr{F}_{S}$, for solar collectors under any operation mode is developed. The thermal efficiency of a CPC and flatplate collector, whether under non-boiling, boiling or superheated conditions, is evaluated using $\mathscr{F}_{S}$ which enables the selection of a suitable collector design and concentration ratio at some specified operational temperature. It is shown that, in general, a CPC has a greater thermal conversion efficiency than a flat-plate for a given operating condition.
\end{abstract}

Eine thermisch-optische Analyse eines Verbund-Parabol-Sonnenkollektors für ein- und mehrphasige Strömung, einschlieBlich Überhitzung

Zusammenfassung. Es wird eine thermische und optische Analyse des Verhaltens eines Verbund-Parabol-Kollektors für die Anwendung der Sonnenenergie vorgestellt, der mit Kältemittel im nichtsiedenden, und übehitzten Bereich arbeitet. Das Verhalten dieses unter ein- und mehrphasigen Bedingungen arbeitenden Kollektors wird bestimmt durch den axialen Anteil der Kühlkanallängen im nichtsiedenden und im überhitzten Zustand. Es werden der mittlere thermische Verlustkoeffizient, die dimensionslose Wärmekapazität sowie die Kollektorwirkungsgrade für verschiedene Zustandsbereiche dieses Parabolspiegels definiert. Ein neuer ,verallgemeinerter Wärmeabflußfaktor", $\mathscr{F}_{S}$, für Sonnenkollektoren, die unter beliebigen Betriebsbedingungen arbeiten, wurde entwickelt. Mit diesem $\mathscr{F}_{S}$-Faktor werden der thermische Wirkungsgrad des Parabolkollektors und eines Plattenkollektors bei einphasiger flüssiger Strömung beim Sieden und für überhitzten Dampf berechnet, wodurch es möglich wird, eine geeignete Kollektorauslegung und das dazugehörige Konzentrationsverhältnis bei vorgegebenen Betriebstemperaturen zu wählen. Es wird gezeigt, daß im allgemeinen der parabolische Kollektor einen höheren thermischen Wirkungsgrad besitzt als der Plattenkollektor bei identischen Betriebsbedingungen.

* Dedicated to Prof. Dr.-Ing. U. Grigull's 75 th birthday

\section{Introduction}

The Compound Parabolic Concentrator (CPC) was invented by Roland Winston in the mid-1960's but it was not until 1974 that the suitability of the CPC for solar energy collection was recognized in the USA [1]. Sponsered by the U.S. Department of Energy after the oil embargo in 1973, extensive research for the development of the CPC took place at Argonne National Laboratories. Winston and Hinterberger [2] developed the theory of light collection within the framework of geometrical optics. Giugler et al. [3] and Thodos and Winston [4] developed principles of cylindrical concentrators and concepts of CPC's used for solar thermal power generation. Once the principles were established, Rabl et al. [5] worked on practical design considerations and their effects on the CPC performance. Collares-Pereira, O'Gallagher, Rabl and Winston [6,7] studied the effect of evacuated receivers which enabled them to build a CPC operating at $300^{\circ} \mathrm{C}$. Also they studied the relation between high temperature performance and optimum concentration ratio [8]. Their results show that with evacuated receiver tubes, at $300^{\circ} \mathrm{C}$, reasonable efficiency is feasible for fixed collectors. On the other hand, at lower temperatures, at about $100^{\circ} \mathrm{C}$, calculations indicated that even nonevacuated CPC collectors with proper design can operate with acceptable efficiency, surpassing that of flat plate collectors $[9,10]$. Hsieh [11] designed a system using CPC collectors to produce industrial process steam. He also performed a comprehensive thermal analysis of a CPC using the Hottel-Whillier-Woertz-Bliss formalism [1]. His predicted results compared well with experiments.

The objective of the present work is to analize a CPC working under non-boiling, boiling and superheated conditions. The CPC cross section is shown in Fig. 1. The overall thermal efficiency of the CPC, $\eta$, is shown to be

$\eta=\mathscr{F}_{S}\left[\eta_{0}-\frac{U_{L}\left(T_{1}-T_{a}\right)}{I R}\right]$ 


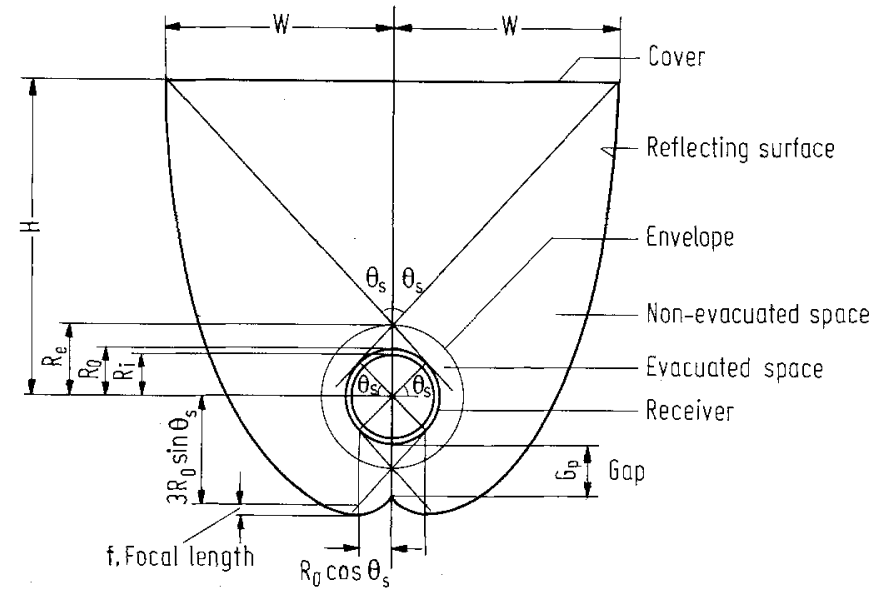

Fig. 1. Cross section of a CPC

where $\mathscr{F}_{S}$ is a new Generalized Heat Removal Factor, $\eta_{0}$ is the optical efficiency, $U_{L}$ is a new overall thermal loss coefficient for a collector operating with multiphase flows, $T_{1}$ and $T_{a}$ are the inlet fluid temperature and the ambient temperature and $I$ is the total incident irradiation. $R$ is the CPC concentration ratio defined as the ratio of the aperture area, $A_{c}$, to the receiver area, $A_{r}$. The analysis includes thermal and optical modeling of the CPC and the parameters which identify its behaviour under these single and multiphase conditions are derived.

\section{Optical efficiency, $\eta_{0}$}

The optical efficiency is related to the process in which the beam or direct component of the incident solar radiation is transmitted through the glass cover of transmissivity $\tau_{c}$, reflected specularly on the mirror surface of reflectivity $\varrho_{m}$, transmitted again through the envelope of transmissivity $\tau_{e}$ and then absorbed by the receiver of absorptivity $\alpha_{r}$. The absorption of the diffuse component of the incident radiation at the receiver also contributes to the optical efficiency and its role will be discussed later. A fraction of the reflected radiation from the mirror escapes from the gap under the receiver and is described in terms of $G_{p}$, the gap length. The fraction of this reflection is defined as $G_{p} / 2 \pi R_{0}$, where $R_{0}$ is the outer receiver radius. This fraction is the ratio of the gap area, $G_{p} L$, to the receiver area, $2 \pi R_{0} L$ where $L$ is the CPC axial length. To allow for this loss, a factor $P$ is defined as

$P=1-\frac{G_{p}}{2 \pi R_{0}}$.

The instantaneous cover transmissivity, $\tau_{c}$, and envelope transmissivity, $\tau_{e}$, are determined by the incident angle, $\theta_{1}$, of the incoming radiation and the optical properties of the cover and envelope material. For a single cover exposed to unpolarized incident radiation, the trans- missivity may be written [12] as

$\tau_{c}=\frac{1}{2}\left[\frac{1-\varrho_{\perp}\left(\theta_{1}\right)}{1+\varrho_{\perp}\left(\theta_{1}\right)}+\frac{1-\varrho_{\|}\left(\theta_{1}\right)}{1+\varrho_{\|}\left(\theta_{1}\right)}\right] e^{-\frac{K_{c} l_{c}}{\cos \theta_{2}}}$

where $\varrho_{\perp}\left(\theta_{1}\right)$ and $\varrho_{\|}\left(\theta_{1}\right)$ are the single interface reflectivities of the perpendicular and parallel components of the incident beam, $\theta_{2}$ is the angle of refraction and $K_{c}$ is the extinction coefficient of the cover material of thickness $l_{c}$. For the envelope, the transmissivity may be written similarly as

$\tau_{a}=\frac{1}{2}\left[\frac{1-\varrho_{\perp}\left(\theta_{1}\right)}{1+\varrho_{\perp}\left(\theta_{1}\right)}+\frac{1-\varrho_{\|}\left(\theta_{1}\right)}{1+\varrho_{\|}\left(\theta_{1}\right)}\right] e^{-\frac{K_{e} l_{e}}{\cos \theta_{2}}}$

where $K_{e}$ is the extinction coefficient of the envelope material of thickness $l_{e}$.

A fraction $\left(1-\alpha_{r}\right)$ from the beam incident on the receiver surface is reflected to the inner surface of the envelope in multiple reflections which contributes to the absorbed energy. To account for this effect, a factor $F$ is defined as

$$
F=\frac{1}{1-\left(1-\alpha_{r}\right) \bar{\varrho}_{d} \frac{A_{r}}{A_{e}}}>1.0 .
$$

$A_{e}$ is the envelope area and $\bar{\varrho}_{d}$ is the diffuse reflectivity from the inner envelope surface. In accordance with standard optical practice [12], the diffuse properties are calculated in the same way as the non-diffuse properties but at an effective angle of incidence equal to $60^{\circ}$.

The useful energy, $q_{b}$, from direct or beam incident energy absorbed by the receiver, is thus formulated as

$q_{b}=A_{c} I_{b} \tau_{c} \varrho_{m} \tau_{e} \alpha_{r} P F$

where $A_{c}$ is the aperture (cover) area, $\mathrm{m}^{2}, I_{b}$ is the beam radiation intensity normal to collector surface, $w / \mathrm{m}^{2}, \varrho_{m}$ is the mirror specular reflectivity and $\alpha_{r}$ is the receiver absorptivity.

The diffuse component of the incident radiation cannot be focused. The back semi-cylindrical surface of the receiver is illuminated only by the mirror, whereas the front surface receives the diffuse radiation directly without reflections. This makes the effective area of for diffuse radiation collection, the receiver area, $A_{r}$, and not the aperture area, $A_{c}$, as in the case of beam radiation.

To determine the diffuse properties of the cover and the envelope, an effective incident angle for diffuse radiation is estimated. In general, for a wide range of conditions encountered in solar collector applications, this effective angle is essentially $60^{\circ}$. Brandemuehl and Beckman [13] integrated the beam transmittance over the appropriate incidence angles and found the effective incidence angle for diffuse, isotopic radiation from the sky and ground reflection to be

$\theta_{e, s}=59.68-0.1388 \beta+0.00149 \beta^{2}$ 
where $\theta_{e, s}$ is the effective incident angle for diffuse sky radiation, degrees, and $\beta$ is the slope angle of the collector, and,

$\theta_{e, g}=90-0.5788 \beta+0.002693 \beta^{2}$

where $\theta_{e, g}$ is the effective incident angle for diffuse ground reflection radiation, degrees.

The cover diffuse transmissivity for sky diffuse radiation, $\bar{\tau}_{c, s}$, is determined by using Eq. (3) with $\theta_{1}=\theta_{e, s}$. The cover diffuse transmissivity for ground reflection diffuse radiation, $\bar{\tau}_{c, g}$, is determined by the use of the same Eq. (3) with $\theta_{1}=\theta_{e, g}$. The diffuse transmissivity of the envelope, $\bar{\tau}_{e}$, is determined in like manner with $\theta_{1}=60^{\circ}$. The diffuse mirror reflectivity and the diffuse receiver absorptivity are assumed to be the same as the direct properties, that is, $\varrho_{m}=\bar{\varrho}_{m}$ and $\alpha_{r}=\bar{\alpha}_{r}$ (the bar denotes that the property is for diffuse radiation). Therefore, the amount of diffuse radiation absorbed by the receiver, $q_{d}$, is:

$q_{d}=A_{r} I_{d, s} \bar{\tau}_{c, s} \bar{\varrho}_{m} \bar{\tau}_{e} \bar{\alpha}_{r} P F+A_{r} I_{d, g} \bar{\tau}_{c, g} \bar{\varrho}_{m} \bar{\tau}_{e} \bar{\alpha}_{r} P F$

where $I_{d, s}$ is the diffuse sky radiation, $w / \mathrm{m}^{2}$, and $I_{d, g}$ is the ground reflection, $w / \mathrm{m}^{2}$. Finally, the optical efficiency, $\eta_{0}$, is defined as the ratio of the total net energy absorbed by the receiver $\left(A_{r}\right)$ to the total incident radiation on the aperture area $\left(A_{c}\right)$. Hence, $\eta_{0}$ is

$\eta_{0}=\frac{q_{b}+q_{d}}{\left(I_{b}+I_{d}\right) A_{c}}$

where $I_{d}=I_{d, s}+I_{d, g}$. Using $q_{b}$ and $q_{d}$ from Eqs. (6) and (9) and noting that $\varrho_{m}=\bar{\varrho}_{m}$ and $\alpha_{r}=\bar{\alpha}_{r}$, the optical efficiency becomes

$\eta_{0}=\frac{\underline{\varrho}_{m} \alpha_{r}\left[R I_{b} \tau_{c} \tau_{e}+\bar{\tau}_{e}\left(I_{d, s} \bar{\tau}_{c, s}+I_{d, g} \bar{\tau}_{c, g}\right)\right] P F}{R\left(I_{b}+I_{d}\right)}$.

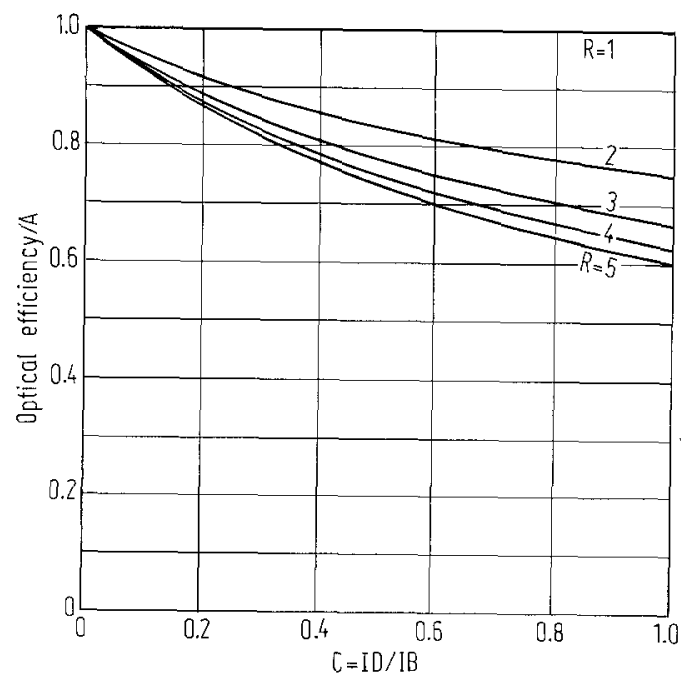

Fig. 2. CPC optical efficiency for $R$ from 1 to 5
Equation (11) represents a new model for the optical efficiency in which the influence of concentration ratio and the direct and diffuse components of the incident radiation are explicitly identified. The solar model of Brandemuehl and Beckman [13] indicates that at high slope angles both $\theta_{e, s}$ and $\theta_{e, g}$ approach $60^{\circ}$. Assuming also that $\bar{\tau}_{c, s}=\bar{\tau}_{c, g}=\bar{\tau}_{c}$, Eq. (11) becomes

$\eta_{0}=\frac{\underline{\varrho}_{m} \alpha_{r}\left(R I_{b} \tau_{c} \tau_{e}+I_{d} \bar{\tau}_{c} \bar{\tau}_{e}\right) P F}{R\left(I_{b}+I_{d}\right)}$.

Considering that multireflections from the parabolic reflectors cause a reorientation of rays such that the reflection pattern becomes diffuse, it can be concluded that as a good approximation $\tau_{e}=\bar{\tau}_{e}$. Furthermore, $\tau_{c}$ is almost constant in the range from $\theta_{1}=0$ to $50^{\circ}$, then decreases slightly in the range from $\theta_{1}=50$ to $65^{\circ}$. Since the effective incident angle for diffuse radiation used in the calculation of $\bar{\tau}_{c}$ is about $60^{\circ}$, it can be concluded that $\bar{\tau}_{c}=\tau_{c}$. Equation (12) then becomes

$\eta_{0}=\frac{\tau_{c} \bar{\tau}_{e} \varrho_{m} \alpha_{r} P F\left(R I_{b}+I_{d}\right)}{R\left(I_{b}+I_{d}\right)}$.

Defining $A$ as

$A=\tau_{c} \bar{\tau}_{e} \varrho_{m} \alpha_{r} P F$

and $C$, the ratio of diffuse radiation to beam radiation, as

$C=\frac{I_{d}}{I_{b}}$

the optical efficiency may be written as

$\eta_{0}=\frac{A\left(\frac{C}{R}+1\right)}{(C+1)} \leqq A$

where $R$ is the concentration ratio defined as $A_{c} / A_{r}$.

This somewhat simplified form for $\eta_{0}$, Eq. (16) shows explicitly that the optical efficiency is reduced significantly as the concentration ratio increases and has a maximum value, $\eta_{0, \max }$, equal to $A$. At the limit, where $R \rightarrow \infty$, $\eta_{0}$ approaches $\frac{A}{C+1}$. For $R=1$ or conditions corresponding to the concentration ratio of flat-plate collectors, $\eta_{0}$ is equal to $A$, its maximum value, and is independent of the value of $C$. This indicates that unlike the flat plate, the CPC optical efficiency is sensitive to the ratio of diffuse to beam radiation. On the other hand, in the absence of diffuse components i.e. $C=0$, which occurs in the extraterrestrial environment, $\eta_{0}$ also reaches its maximum value, $A$, and is independent of the concentration ratio. For conditions in which only a diffuse field exists, that is, $I_{b}=0, \eta_{0}$ reaches its minimum asymptotic value which is $\eta_{0, \min }=A / R$. Figure 2 shows the ratio of $\eta_{0} / A$ as a function of $C$ and $R$ derived from Eq. (16). For conditions of clear skies, the value of $C$ will range from 0.05 to 0.15 . 


\section{Thermal loss coefficients, $U_{N B}, U_{B}$ and $U_{S}$}

The radiative loss from the receiver to the envelope, $q_{r, e}^{r}$ is formulated as

$q_{r, e}^{r}=U_{r, e}\left(T_{r}-T_{e}\right) A_{r}$.

The coefficient $U_{r, e}$ is defined as

$U_{r, e}=\frac{\sigma\left(T_{r}^{2}+T_{e}^{2}\right)\left(T_{r}+T_{e}\right)}{\frac{1}{\varepsilon_{r}}+\frac{A_{r}}{A_{e}}\left(\frac{1}{\varepsilon_{e}}-1\right)}$

where $T_{r}$ is the receiver temperature, $\mathrm{K}, T_{e}$ is the envelope temperature, $\mathrm{K}, \varepsilon_{r}$ is the receiver emmissivity, $\varepsilon_{e}$ is the envelope emissivity and $A_{e}$ is the envelope area, $\mathrm{m}^{2}$. Due to the fact that the mirror has a high specular reflectivity, on the order of 0.96 , and its back surface is insulated, it is assumed that the dominant losses from the envelope are those to the cover. Hence, the thermal loss coefficient from the envelope to the cover, $U_{e, c}$, may be written as

$$
U_{e, c}=\frac{\sigma\left(T_{e}^{2}+T_{c}^{2}\right)\left(T_{e}+T_{c}\right)}{\frac{1}{\varepsilon_{e}}+\frac{A_{e}}{A_{c}}\left(\frac{1}{\varepsilon_{c}}-1\right)}+1.32\left(\frac{T_{e}-T_{c}}{2 R_{e}}\right)^{0.25}
$$

where $T_{c}$ is the cover temperature, $\mathrm{K}, \varepsilon_{c}$ is the cover emissivity, and $R_{e}$ is the envelope radius, $\mathrm{m}$. The first term in Eq. (19) accounts for radiative losses and the second term is the natural convection heat transfer coefficient. Similar, from the cover to the sky and ambient air, the heat loss coefficient, $U_{c, a}$, is

$U_{c, a}=\frac{\sigma \varepsilon_{c}\left(T_{c}^{4}-T_{s}^{4}\right)}{T_{c}-T_{a}}+h_{a}$

where $T_{a}$ is the ambient temperature and $T_{s}$ is the absolute sky temperature given by Swinbank [14] as $T_{s}=0.0552 T_{a}^{1.5}$. The forced convection heat transfer coefficient, $h_{a}$, estimated as a function of ambient air temperature and wind velocity by Sparrow et al. [15] as $N u=0.86 \operatorname{Re}^{1 / 2} \operatorname{Pr}^{1 / 3}$, where the characteristic length is four times the cover area divided by the cover perimeter. Based on the receiver area, each of the overall thermal loss coefficients, $U_{N B}, U_{B}$ and $U_{S}$ for the non-boiling, boiling and superheated regions, respectively, can be expressed as

$\frac{1}{U_{i} A_{r}}=\frac{1}{U_{r, e} A_{r}}+\frac{1}{U_{e, c} A_{e}}+\frac{1}{U_{c, a} A_{c}}$

where the subscript $i$ refers to $N B, B$ and $S$. An effective way to decrease the value of $U_{i}$, regardless the receiver temperature, is to use a low infrared emissivity coating on the outside receiver surface. Such a coating could decrease the emissivity, $\varepsilon_{r}$, from that of the uncoated surface of $0.85-0.90$ to values on the order of $0.10-0.15$, and have a significant effect on decreasing the value of $U_{i}$.
The CPC component's temperatures $T_{r}, T_{e}$ and $T_{c}$ are determined using a thermal analysis of the non-boiling, boiling and superheating region of the CPC under steadystate or transient conditions as outlined in reference [16].

\section{Generalized heat removal factor, $\mathscr{F}_{S}$}

For a generalized model of flow, the coolant with subcooled inlet conditions undergoes non-boiling, boiling and superheating during its passage through the CPC. The total useful energy by solar conversion will be written for this process as

$q_{u}=q_{u, N B}+q_{u, B}+q_{u, s}$

where $q_{u, N B}, q_{u, B}$ and $q_{u, S}$ are the useful energy gains in the non-boiling, boiling and superheating region, as illustrated in Fig. 3.

In the non-boiling region, the rate of increase in the fluid enthalpy in the flow direction is

$w c_{p l} \frac{d T}{d z}=F^{\prime}\left[I R \eta_{0}-U_{N B}\left(T-T_{a}\right)\right] 2 \pi R_{0}$

where $w$ is the fluid mass flow rate, $\mathrm{kg} / \mathrm{s}, c_{p l}$ is the liquidphase specific heat, $\mathrm{J} / \mathrm{kg} \mathrm{K}$, and $I$ is the total incident irradiation equal to $I_{b}+I_{d}, w . F^{\prime}$ is the collector efficiency factor for the non-boiling region [12] and is defined as

$$
F^{\prime}=\frac{\frac{1}{U_{N B}}}{\frac{1}{U_{N B}}+\frac{R_{0} \ln \frac{R_{0}}{R_{i}}}{k_{w}}+\frac{R_{0}}{h_{l} R_{i}}}
$$

where $k_{w}$ is the thermal conductivity of the receiver wall material, $w / \mathrm{m} \mathrm{K}$ and $h_{l}$ is the convective heat transfer

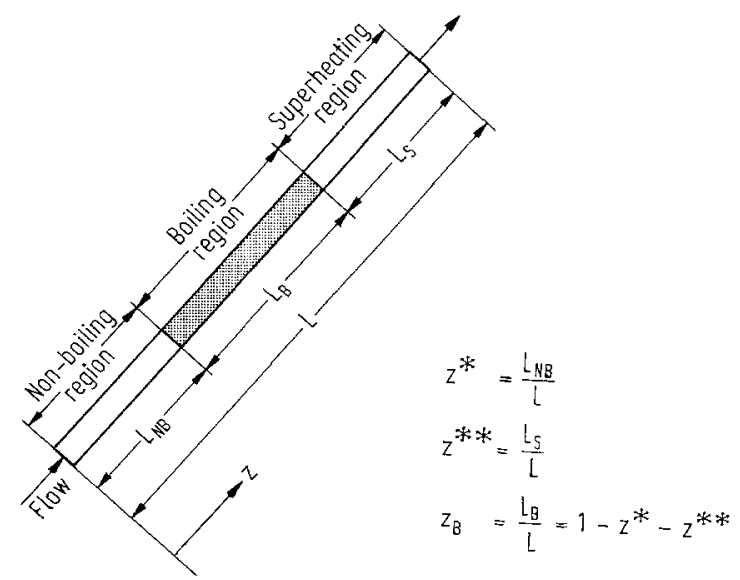

Fig. 3. Illustration of single and multiphase flows, including superheat, in the CPC 
coefficient, $w / \mathrm{m}^{2} \mathrm{~K}$, for the fluid as given by Brown and Ganvin model [17].

Integrating over the non-boiling length, $L_{N B}$, gives

$$
\int_{T_{1}}^{T_{\text {sat }}} \frac{d T}{\frac{I R \eta_{0}}{U_{N B}}-\left(T-T_{a}\right)}=\int_{0}^{L_{N B}} \frac{U_{N B} F^{\prime} 2 \pi R_{0}}{w c_{p l}} d z
$$

or,

$\frac{I R \eta_{0}-U_{N B}\left(T_{\mathrm{sat}}-T_{a}\right)}{I R \eta_{0}-U_{N B}\left(T_{1}-T_{a}\right)}=e^{-a_{n} z^{*}}$

where $T_{1}$ is the fluid inlet temperature, $T_{\text {sat }}$ is the saturation temperature and $z^{*}$ is the dimensionless length of the non-boiling region defined as $L_{N B} / L$ by Al-Tamimi and Clark [18]. The parameter $a_{R}$ is the dimensionless capacitance rate for non-boiling conditions and defined as

$a_{R}=\frac{F^{\prime} U_{N B}}{\left(w / A_{c}\right) c_{p l} R}$

Therefore, $q_{u, N B}$ can also be written as

$q_{u, N B}=w c_{p l}\left(T_{\text {sat }}-T_{1}\right)=w c_{p l}\left[\left(T_{\text {sat }}-T_{a}\right)-\left(T_{1}-T_{a}\right)\right]$.

Substituting Eq. (26) into Eq. (28) and rearranging gives

$q_{u, N B}=\frac{F^{\prime}}{a_{R}}\left(1-e^{-a_{R} z^{*}}\right) A_{r}\left[I R \eta_{0}-U_{N B}\left(T_{1}-T_{a}\right)\right]$.

In the boiling region, the enthalpy increase of the fluid is written as

$d q_{u, B}=F_{B}^{\prime}\left[I R \eta_{0}-U_{B}\left(T_{\text {sat }}-T_{a}\right)\right] 2 \pi R_{0} d z$

where $F_{B}^{\prime}$ is the collector efficiency factor for the boiling region defined in the same way as $F^{\prime}$, Eq. (24), except that the convective heat transfer coefficient is for the twophase boiling and is determined using the McNelly model [19]. $F_{B}^{\prime}$ is therefore

$$
F_{B}^{\prime}=\frac{\frac{1}{U_{B}}}{\frac{1}{U_{B}}+\frac{R_{0} \ln \frac{R_{0}}{R_{i}}}{k_{w}}+\frac{R_{0}}{h_{b} R_{i}}} .
$$

For the same receiver temperature as in the boiling region, integrating Eq. (30) for non-boiling conditions, that is

$$
\int_{T_{1}}^{T_{\mathrm{sat}}} \frac{d T}{\frac{I R \eta_{0}}{U_{B}}-\left(T-T_{a}\right)}=\int_{0}^{L_{N B}} \frac{U_{B} F_{b}^{\prime} 2 \pi R_{0}}{w c_{p l}} d z
$$

we get

$$
\frac{I R \eta_{0}-U_{B}\left(T_{\mathrm{sat}}-T_{a}\right)}{I R \eta_{0}-U_{B}\left(T_{1}-T_{a}\right)}=e^{-a_{R b} z^{*}}
$$

where $a_{R b}$ is defined as

$a_{R b}=\frac{F_{b}^{\prime} U_{B}}{\left(w / A_{c}\right) c_{p l} R}$

and $F_{b}^{\prime}$ defined as

$$
F_{b}^{\prime}=\frac{\frac{1}{U_{B}}}{\frac{1}{U_{B}}+\frac{R_{0} \ln \frac{R_{0}}{R_{i}}}{k_{w}}+\frac{R_{0}}{h_{l} R_{i}}} .
$$

$F_{b}^{\prime}$ is approximately equal to $F^{\prime}$ and hence $a_{R b}$ can be approximated as $a_{R} \frac{U_{B}}{U_{N B}}$. Integrating Eq. (30) from $z=L_{N B}$ to $z=L-L_{S}$, noting that the temperature of the two-phase mixture, $T_{\text {sat }}$, is constant and introducing Eq. (33), yields.

$q_{u, B}=F_{B}^{\prime} A_{r}\left(1-z^{*}-z^{* *}\right)\left[I R \eta_{0}-U_{B}\left(T_{1}-T_{a}\right)\right] e^{-a_{R b} z^{*}}$

where $z^{* *}$ is the dimensionless superheating region length defined as $L_{S} / L$.

In the superheating region, the increase in fluid enthalpy is written as

$d q_{u, S}=F_{S}^{\prime}\left[I R \eta_{0}-U_{S}\left(T-T_{a}\right)\right] 2 \pi R_{0} d z=w c_{p g} d T$

where $c_{p g}$ is the specific heat of the vapor phase, $\mathrm{J} / \mathrm{kg} \mathrm{K}$ and $F_{S}^{\prime}$ is the collector efficiency factor of the superheating region given as

$F_{S}^{\prime}=\frac{\frac{1}{U_{S}}}{\frac{1}{U_{S}}+\frac{R_{0} \ln \frac{R_{0}}{R_{i}}}{k_{w}}+\frac{R_{0}}{h_{s} R_{i}}}$

where $U_{S}$ is the thermal loss coefficient for the superheating region, $w / \mathrm{m}^{2} \mathrm{~K}$ and $h_{s}$ is the convective heat transfer coefficient, $w / \mathrm{m}^{2} \mathrm{~K}$, for the superheated vapor, using the Brown and Ganvin model [17]. Integrating Eq. (37) over the superheating region, figure 3 , yields

$\int_{T_{\mathrm{sat}}}^{T_{2 s}} \frac{d T}{\frac{I R \eta_{0}}{U_{S}}-\left(T-T_{a}\right)}=\int_{L_{N B}+L_{B}} \frac{U_{S} F_{S}^{\prime} 2 \pi R_{0}}{w c_{p g}} d z$

or

$\frac{I R \eta_{0}-U_{S}\left(T_{2 s}-T_{a}\right)}{I R \eta_{0}-U_{S}\left(T_{\text {sat }}-T_{a}\right)}=e^{-\frac{U_{S} F_{S}^{\prime} 2 \pi R_{0} L_{S}}{w c_{p s}}}$

where $T_{2 s}$ is the outlet superheated vapor temperature, $\mathrm{K}$. A parameter similar to $a_{R}$ for the non-boiling region may be defined for the superheating region as

$a_{S R}=\frac{U_{S} F_{S}^{\prime}}{\left(w / A_{c}\right) c_{p g} R}$

which can be introduced into the exponential term in 
Eq. (40) to give

$\frac{I R \eta_{0}-U_{S}\left(T_{2 s}-T_{a}\right)}{I R \eta_{0}-U_{S}\left(T_{\mathrm{sat}}-T_{a}\right)}=e^{-a_{S R} z^{* *}}$

The useful energy gain in the superheating region, $q_{u, s}$ is

$q_{u, S}=w c_{p g}\left(T_{2 s}-T_{\text {sat }}\right)$

or, alternatively,

$q_{u, S}=\frac{w c_{p g}}{U_{S}}\left\{\left[I R \eta_{0}-U_{S}\left(T_{\text {sat }}-T_{a}\right)\right]-\left[I R \eta_{0}-U_{S}\left(T_{2 s}-T_{a}\right)\right]\right\}$

Substituting Eq. (42) into Eq. (44) and rearranging, yields

$q_{u, S}=\frac{F_{S}^{\prime}}{a_{S R}}\left(1-e^{-a_{S R} z^{* *}}\right) A_{r}\left[\operatorname{IR} \eta_{0}-U_{S}\left(T_{\mathrm{sat}}-T_{a}\right)\right]$.

For the same receiver temperature as in the superheating region, integrating Eq. (37) for non-boiling conditions, that is

$$
\int_{T_{1}}^{T_{\text {sat }}} \frac{d T}{\frac{I R \eta_{0}}{U_{S}}-\left(T-T_{a}\right)}=\int^{L_{N B}} \frac{U_{S} F_{s}^{\prime} 2 \pi R_{0}}{w c_{p l}} d z
$$

we get

$$
\frac{I R \eta_{0}-U_{S}\left(T_{\text {sat }}-T_{a}\right)}{I R \eta_{0}-U_{S}\left(T_{1}-T_{a}\right)}=e^{-a_{R s} z^{*}}
$$

where $a_{R s}$ is defined as

$$
a_{R s}=\frac{F_{s}^{\prime} U_{S}}{\left(w / A_{c}\right) c_{p l} R}
$$

The total useful energy collected by a CPC under nonboiling, boiling and superheated fluid conditions is found by combining the results in Eq. (29), (36) and (50) into Eq. (22) to give

$$
\begin{aligned}
q_{u}=F_{R} A_{r} & {\left[\frac{1-e^{-a_{R} z^{*}}}{1-e^{-a_{R}}}+\frac{\left(1-z^{*}-z^{* *}\right) e^{-a_{R b} z^{*}}}{F_{R} / F_{B}^{\prime}}\right.} \\
& \left.+\frac{\left(1-e^{-a_{S R} z^{* *}}\right) e^{-a_{R_{s} z^{*}}}}{a_{S R} F_{R} / F_{S}^{\prime}}\right]\left[I R \eta_{0}-U_{L}\left(T_{1}-T_{a}\right)\right],
\end{aligned}
$$

where $F_{R}$ is the heat removal factor for a non-boiling collector having the same mass flow rate per unit aperture area as $\mathrm{CPC}$ and is defined as

$F_{R}=\frac{F^{\prime}}{a_{R}}\left(1-e^{-a_{R}}\right)=F^{\prime \prime} F^{\prime}$

where $F^{\prime \prime}$ is the collector flow factor. The first bracketed term in Eq. (51) may be defined as

$$
\begin{aligned}
F_{S}=\frac{1-e^{-a_{R} z^{*}}}{1-e^{-a_{R}}} & +\frac{\left(1-z^{*}-z^{* *}\right)}{F_{R} / F_{B}^{\prime}} e^{-a_{R b} z^{*}} \\
& +\frac{\left(1-e^{-a_{S R} z^{* *}}\right) e^{-a_{R s} z^{*}}}{a_{S R} F_{R} / F_{S}^{\prime}} .
\end{aligned}
$$

Accordingly, from Eq. (52) and (53), a new Generalized Heat Removal Factor, $\mathscr{F}_{S}$, describing the pérformance of a CPC in which these simultaneous states of flow exist, namely, subcooled, non-boiling, boiling and superheated conditions, may be defined as

$\mathscr{F}_{S}=F_{R} F_{S}$.

The overall thermal loss coefficient, $U_{L}$, in Eq. (51) is equal to

$$
U_{L}=\frac{\frac{F^{\prime}}{a_{R}}\left(1-e^{-a_{R} z^{*}}\right) U_{N B}+F_{B}^{\prime}\left(1-z^{*}-z^{* *}\right) e^{-a_{R b} z^{*}} U_{B}+\frac{F_{S}^{\prime}}{a_{S R}}\left(1-e^{-a_{S R} z^{* *}}\right) e^{-a_{R s} z^{*}} U_{S}}{\frac{F^{\prime}}{a_{R}}\left(1-e^{-a_{R} z^{*}}\right)+F_{B}^{\prime}\left(1-z^{*}-z^{* *}\right) e^{-a_{R b} z^{*}}+\frac{F_{S}^{\prime}}{a_{S R}}\left(1-e^{-a_{S R} z^{* *}}\right) e^{-a_{R S} z^{*}}}
$$

and $F_{s}^{\prime}$ defined as

$$
F_{s}^{\prime}=\frac{\frac{1}{U_{S}}}{\frac{1}{U_{S}}+\frac{R_{0} \ln \frac{R_{0}}{R_{i}}}{k_{w}}+\frac{R_{0}}{h_{l} R_{i}}} .
$$

Introducing Eq. (47) into (45), yields

$$
q_{u, S}=\frac{F_{S}^{\prime}}{a_{S R}}\left(1-e^{-a_{S B} z^{* *}}\right) A_{r}\left[I R \eta_{0}-U_{S}\left(T_{1}-T_{a}\right)\right] e^{-a_{R s} z^{*}}
$$

Hence, $q_{u}$ is written as:

$q_{u}=\mathscr{F}_{S} A_{r}\left[I R \eta_{0}-U_{L}\left(T_{1}-T_{a}\right)\right]$.

From which the thermal conversion efficiency, $\eta$, becomes

$\eta=\mathscr{F}_{S}\left[\eta_{0}-\frac{U_{L}\left(T_{1}-T_{a}\right)}{I R}\right]$.

The Generalized Heat Removal Factor $\mathscr{F}_{S}$ is an extension of the heat removal factor $\mathscr{F}_{S}$ developed by $\mathrm{Al}$ Tamimi and Clark [18] for boiling flat-plate collectors having saturated discharge states. The present extension includes the effects of both concentration and superheated discharge states. The functional dependence of $\mathscr{F}_{S}$ on the several operational variables and parameters is found 
from Eqs. (52) and (53) to be

$\mathscr{F}_{S}=f\left(a, a_{S R}, R, \frac{F_{B}^{\prime}}{F^{\prime}}, \frac{F_{S}^{\prime}}{F^{\prime}}, F^{\prime}, z^{*}, z^{* *}\right)$.

For boiling flat-plate collectors having saturated discharge states, the heat removal factor $\mathscr{F}_{R}$, developed by AlTamimi and Clark [18], is represented as

$\mathscr{F}_{R}=f\left(a, \frac{F_{B}^{\prime}}{F^{\prime}}, F^{\prime}, z^{*}\right)$

where $a^{-1}=\frac{\left(w / A_{c}\right) c_{p l}}{F^{\prime} U_{N B}}$. The greater generalization in process description provided by $\mathscr{F}_{S}$ is evident in the comparison of Eqs. (58) and (59). Values of the terms $z^{*}$ and $z^{* *}$ in the generalized heat removal factor $\mathscr{F}_{S}$ are determined from a thermal analysis of the channel flow, as in references [10] and [18]. Thus,

$z^{*}=\frac{1}{a_{R}} \ln \frac{\eta_{T_{1}}}{\eta_{T_{\mathrm{sat}}}}$

and

$z^{* *}=\frac{1}{a_{S R}} \ln \frac{\eta_{T_{\mathrm{sat}}}}{\eta_{T_{2 \mathrm{~s}}}}$

where $\eta_{T_{1}}, \eta_{T_{\text {sat }}}$ and $\eta_{T_{2 s}}$ are the efficiencies of the singlephase (non-boiling) collector at inlet temperatures $T_{1}, T_{\text {sat }}$ and $T_{2 s}$, respectively.

\section{Discussion}

An evaluation of the significance of these results rests mainly on an examination of the influence of the concentration ratio $R$ and other parameters on the value of the new Generalized Heat Removal Factor, $\mathscr{F}_{S}$. However, owing to its fairly complex mathematical form, it is difficult to perform an algebraic evaluation of this function. Instead, its functional relationship with respect to concentration ratio will be determined by computer simulation for a set of fixed, but normal, operating conditions. These results will be given later, but first some useful insights may be found by an examination of the function $F^{\prime \prime}$, the collector flow factor, which is also equal to $F_{R} / F^{\prime}$ as shown in Eq. (52). The factor $\mathscr{F}_{S}$ is dependent on the factor $F_{R}$ as given in Eq. (54).

The flow factor $F^{\prime \prime}$ is shown in Fig. 4 as a function of $\frac{R}{a_{R}}$, which is also equal to $\frac{\left(w / A_{c}\right) c_{p l}}{F^{\prime} U_{N B}}$, defined as $a^{-1}$, and the concentration ratio $R$. As will be noted for a fixed flow rate per unit area, $w / A_{c}$, the factor $F^{\prime \prime}$ is increased as the concentration ratio increases, especially at values of $\frac{\left(w / A_{c}\right) c_{p l}}{F^{\prime} U_{N B}}$ less than 1.0. This corresponds to moderate to low flow rates of the coolant. At larger flow rates, or smaller values of $a$, the influence of concentration ratio is diminished and at very large flow rates (or very small values of $a$ ) the influence of concentration ratio vanishes. Under the later circumstances, however, the useful energy from the CPC would increase with increasing concentration ratio, as shown by Eq. (56), owing largely to a proportional reduction in thermal losses at the higher concentration ratios.

For the results in Fig. 4, the curve for $R=1.0$ corresponds to conditions of a flat-plate collector. Hence, these results indicate the significant improvement in thermal performance provided by a CPC over that of a flat-plate, particularly at concentration ratios greater than 2.0.

The evaluation of the thermal performance of the CPC under the operating conditions described is effectively done by examining the characteristics of the new Generalized Heat Removal Factor, $\mathscr{F}_{S}$, Eq. (54), and its role in determining the useful energy, $q_{u}$, and thermal conversion efficiency, $\eta$, Eqs. (56) and (57). To accomplish this, $\mathscr{F}_{S}$ has been computed using computer simulation for a fixed set of operating conditions using R-11 as the coolant fluid at a flow rate per unit aperture area of $0.0025 \mathrm{~kg} / \mathrm{s} \mathrm{m}^{2}$. The results of this simulation are given in Figs. 5 through 8 corresponding to concentration ratios, $R=1,2,3$, and 5 . Further, to simplify this representation the transfer coefficients $U_{N B}, U_{B}$ and $U_{S}$ and $h_{l}$ and $h_{b}$ will be taken to be the same, respectively. Other situations can be considered. This is a practical, realistic approximation as can be seen from their defining equations.

For this representation $\mathscr{F}_{S}$ is shown to be determined by the parameters $z^{*}, z^{* *}$ and $z_{B}$ for each concentration ratio. The dimensionless superheated channel length, $z^{* *}$, ranges from 0.0 to 0.7 although as a practical matter it would be expected to normally be less than 0.4 . For greater values,

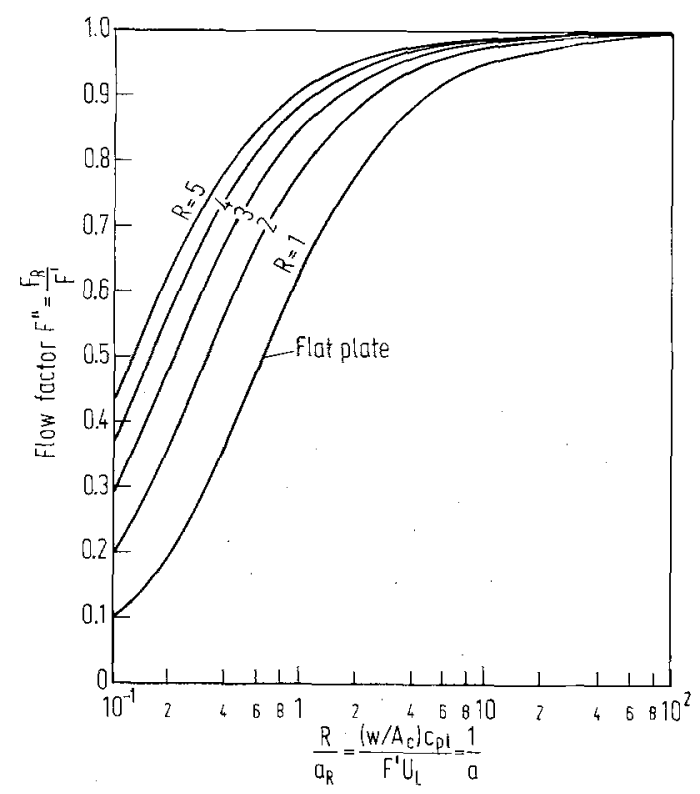

Fig. 4. Collector flow factor $F^{\prime \prime}=F_{R} / F^{\prime}$ 


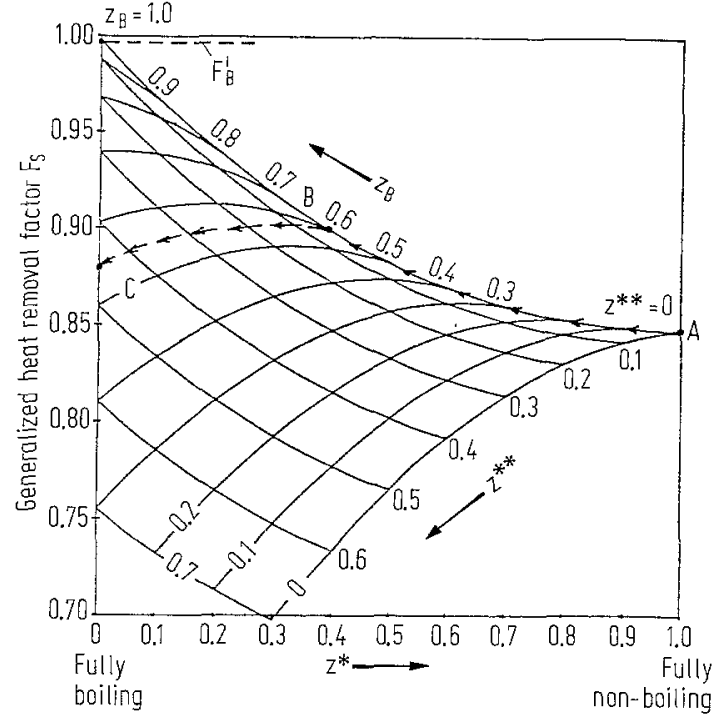

Fig. 5. Generalized Heat Removal Factor $\mathscr{F}_{S}$ for $R=1$

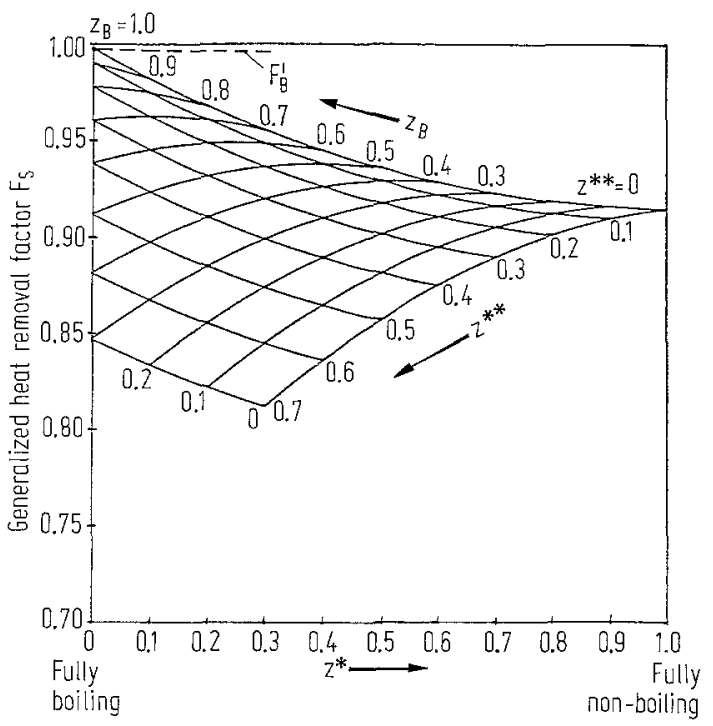

Fig. 6. Generalized Heat Removal Factor $\mathscr{F}_{S}$ for $R=2$

the exit superheat would be very large, probably exceeding $200{ }^{\circ} \mathrm{C}$, and thus produce an unacceptably poor conversion efficiency for most purposes. Certain operating limits may be identified for $\mathscr{F}_{S}$. When $z^{*}=1.0$, the CPC would be operating in a fully non-boiling mode (point $A$, Fig. 5) as a concentrator cooled by a coolant in singlephase flow. Under normal operating conditions as the incident solar irradiation, $I$, is increased or as the inlet sub-cooling, $T_{\text {sat }}-T_{1}$, is decreased, boiling will begin at the downstream positions of the receiver tube. As the boiling process develops further (and with a saturated exit state, i.e. $z^{* *}=0.0$ ) the values of $\mathscr{F}_{S}$ will increase, following the path from $A$ to $B$, Fig. 5 . There will be generally

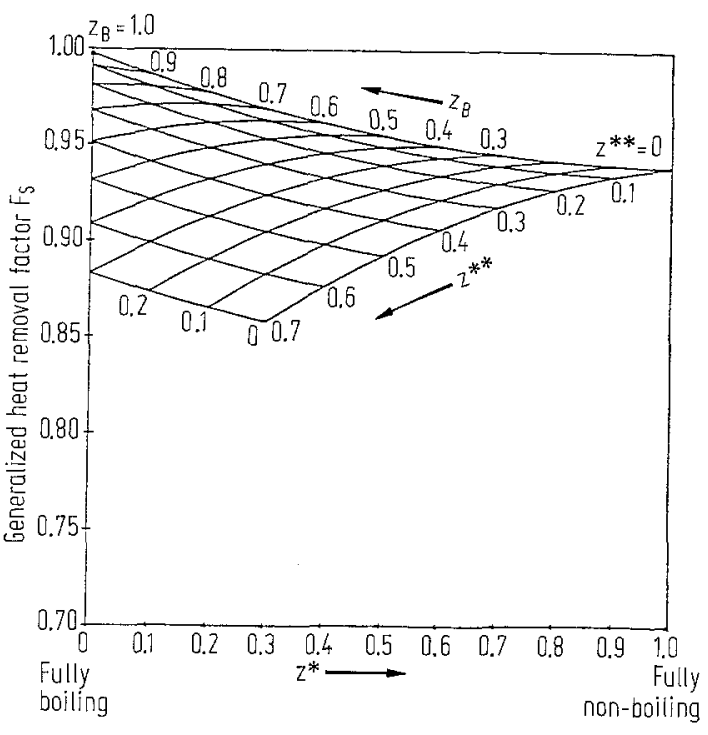

Fig. 7. Generalized Heat Removal Factor $\mathscr{F}_{S}$ for $R=3$

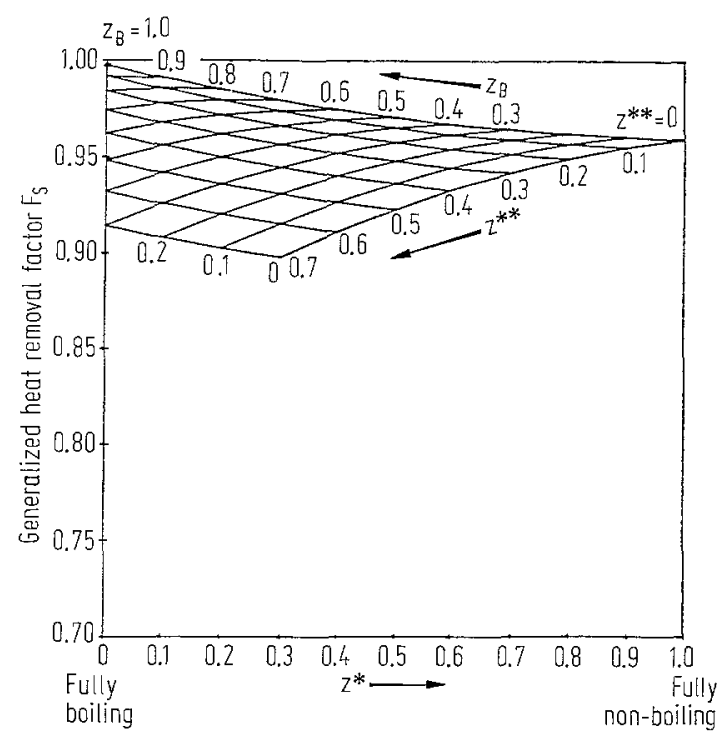

Fig. 8. Generalized Heat Removal Factor $\mathscr{F}_{S}$ for $R=5$

some point $B$ at which the exit state becomes that of a saturated vapor and any further increases in the incident solar irradiation, $I$, will cause the exit state to become superheated. The subsequent values of $\mathscr{F}_{S}$ corresponding to these superheated exit states are shown as the path $B$ to $C$, Fig. 5, with a consequent (probable) reduction in $\mathscr{F}_{S}$ resulting from a proportional increase in the thermal losses. The limit of this process would be the value of $\mathscr{F}_{S}$ corresponding to point $C$, with $z^{*}=0.0$, which describes a fully boiling condition existing from the inlet, a superheated length $z^{* *}$ of approximately 0.45 and a boiling length $z_{B}$ of about 0.55 . A large number of other states of course are possible, each depending on the specific 


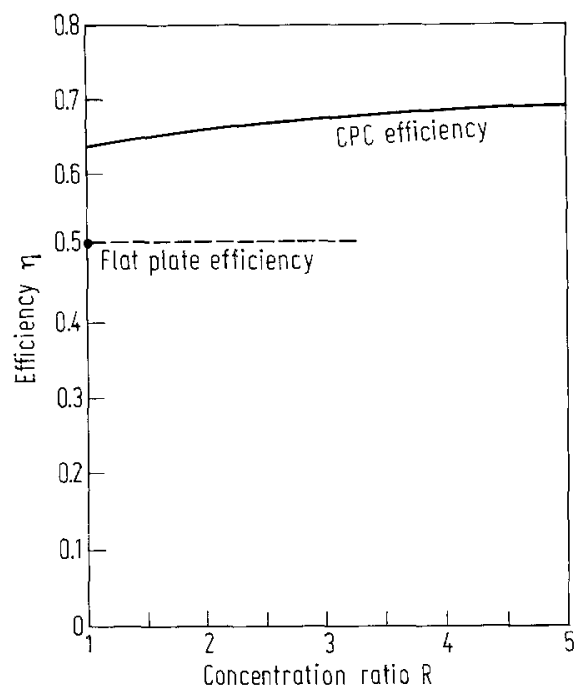

Fig. 9. Collector thermal efficiency versus the concentration ratio at $\frac{T_{1}-T_{a}}{I}=0, p_{1}=0.7 \mathrm{MPa}, T_{2 s}=150^{\circ} \mathrm{C}, I=900 \mathrm{w} / \mathrm{m}^{2}, T_{a}=$ $20^{\circ} \mathrm{C}$ and $A_{c}=4 \mathrm{~m}^{2}$

Table 1. Collector parameters and thermal efficiency at $\frac{T_{1}-T_{a}}{I}=0, p_{1}=0.7 \mathrm{MPa}, T_{2 s}=150^{\circ} \mathrm{C}, I=900 \cdots / \mathrm{m}^{2}, T_{a}=20^{\circ} \mathrm{C}$ and $A_{c}=4 \mathrm{~m}^{2}$

\begin{tabular}{llllll}
\hline$R$ & $z^{*}$ & $z^{* *}$ & $\mathscr{F}_{S}$ & $\eta$ & $w(\mathrm{~kg} / \mathrm{s})$ \\
\hline 5 & 0.304 & 0.104 & 0.986 & 0.690 & 0.01022 \\
4 & 0.280 & 0.110 & 0.975 & 0.685 & 0.01015 \\
3 & 0.250 & 0.120 & 0.965 & 0.675 & 0.01000 \\
2 & 0.220 & 0.133 & 0.943 & 0.660 & 0.00980 \\
1 & 0.186 & 0.152 & 0.911 & 0.638 & 0.00945 \\
Flat & & & & & \\
plate & 0.160 & 0.321 & 0.651 & 0.507 & 0.00751 \\
\hline
\end{tabular}

operating conditions and circumstances. These states can be identified using Eqs. (51) through (61) once the operating conditions are established.

Certain other limits for $\mathscr{F}_{S}$ may be discussed. For the conditions of saturated exit states, the values of $\mathscr{F}_{S}$ all fall along the upper curve corresponding to $z^{* *}=0.0$. These are the conditions identified by Al-Tamimi and Clark [18] for flat-plate having $R=1$. For a fully boiling condition, $z^{*}=0.0$, the maximum value of $\mathscr{F}_{S}$ is $F_{B}^{\prime}$, which corresponds to flows having saturated exit states. The general conditions, however, including the effects of exit superheat are described as those states falling below the $z^{* *}=0.0$ limit.

The effect of concentration ratio can be seen by comparing the values of $\mathscr{F}_{S}$ in Figs. 5 through 8, where the concentration ratio values vary from 1 to 5 . Clearly, for this operating condition an increase in the concentration ratio significantly increases $\mathscr{F}_{S}$. The related increase in the useful energy, $q_{u}$, is even greater because of the propor- tional reduction in thermal losses with increased concentration.

It is instructive to determine some specific operating parameters of a CPC under fixed inlet and superheated outlet conditions for the range of concentration ratios from 1 to 5 and compare such results with those corresponding to a flat-plate collector operating in a boiling mode also having the same superheated exit state. For these calculations the coolant is R-11 operating at a pressure $p_{1}=0.7 \mathrm{MPa}$ with inlet and outlet temperatures of $20^{\circ} \mathrm{C}$ and $150^{\circ} \mathrm{C}$. This represents an exit superheat of $57.6^{\circ} \mathrm{C}$. The incident solar irradiation is $900 \mathrm{w} / \mathrm{m}^{2}$ falling on an aperture area of $4 \mathrm{~m}^{2}$.

The results of this calculation and the conditions for which they are made are summarized in Table 1 and Fig. 9. As may be seen the effect of increasing concentration ratio, $R$, on $\mathscr{F}_{S}$ and $\eta$ are very significant. The corresponding changes in $z^{*}$ and $z^{* *}$ with $R$ are included in Table 1. Of importance also is the comparative performance of a CPC at various concentration ratios with that of a flat-plate collector given in the bottom line of the table. In this case an increase in the conversion efficiency of $36 \%$ is obtained from a CPC with a concentration ratio of 5 .

It is to be noted that the results shown for $R=1$ are for the CPC configuration shown in Fig. 1. The flat plate used for this comparison is manufactured by Solar Research Division, Refrigeration Research Incorporated, Brighton, Michigan, USA and in common use in the USA for boiling solar systems. To obtain the fixed fluid conditions at the collector outlet, the mass flow rate is reduced to $0.00751 \mathrm{~kg} / \mathrm{s}$ for the same insolation and aperture area of $900 \mathrm{w} / \mathrm{m}^{2}$ and $4 \mathrm{~m}^{2}$. Because the flat-plate considered is single-glazed and non-evacuated, its thermal loss coefficient, $U_{L}$, is greater than a CPC with $R=1$. The flat-plate thermal efficiency is $50.7 \%$ compared to $63.8 \%$, the CPC thermal efficiency at $R=1$.

\section{Acknowledgements}

The authors wish to acknowledge the interest and helpful support of this research by Mr. Edward W. Bottum, President, Solar Research Division, Refrigeration Research Inc., Brighton, Michigan, USA.

\section{References}

1. Hsieh, C. K. Thermal analysis of CPC collectors. Solar Energy (1981) 19-29

2. Winston R.; Hinterberger, H.: Principles of cylindrical concentrations for solar energy. Solar Energy 17 (1975) 255

3. Giugler, R.: Compound parabolic concentrators for solar thermal power. Argonne National Lab., Rep. ANL-75-52, 1975

4. Thodos, G.; Winston, R.: Development and demonstration of compound parabolic concentrators for solar thermal power generation. Argonne National Lab., Rep. ANL-76-71, 1976

5. Rabl, A.; Goodman, N. B.; Winston, R.: Practical design considerations for CPC solar collectors. Solar Energy 22 (1979) 373 
6. O'Gallagher, J.; Collares-Pereira, M.; Rabl, A.; Winston, R.: A compound parabolic concentrator for operation at $300^{\circ} \mathrm{C}$. Proc. of the 1978 annual meeting, American Section of ISES, Denver 1 (1978) 885

7. Winston, R.; O'Gallagher, J.: Non-imaging concentrators for solar thermal energy. Rep. DOE/ET/20236-18, 1980

8. Collares-Pereira, M. et al.: High temperature solar collectors of optimal concentration. Proc. Int. Solar Energy Society meeting, New Delhi 1978

9. Collares-Pereira, $M$. et al.: Design and performance characteristics of compound parabolic concentrator with evacuated and non-evacuated receivers. Proc. ISES congress, Atlanta, GA, 2 (1979) 1295

10. Rabl, A.: Optical and thermal properties of compound parabolic concentrators. Solar Energy 18 (1976) 497-511

11. Hsieh, C. K: Design of a system using CPC collectors to collect solar energy and to produce industrial process steam. Argonne National Lab., Rep. ANL-79-102, 1979

12. Duffie, J. A.; Beckman, W. A.: Solar engineering of thermal processes. New York: John Wiley 1980

13. Brandemuehl, M. J.; Beckman, W. A.: Transmission of diffuse radiation through $\mathrm{CPC}$ and flat plate collector glazings. Solar Energy 24 (1980) 511-513

14. Swinbank, W. C.: Long-wave radiation from clear skies. Q. J. R. Meteorol. Soc. 89 (1983)

15. Sparrow, E. M.; Ramsey, J. W.; Mass, E. A.: Effect of finite width on heat transfer and fluid flow about an inclined rectangular plate: J. Heat Transfer, Trans. ASME 101 (1979) 2
16. El-Assy, A. Y.: Technical and economic analysis of the thermal performance of a solar boiling concentrator for power generation. Ph.D. Thesis. Univ. Michigan, Ann Arbor 1986

17. Brown, C. K: Ganvin, W. H.: Combined free and forced convection I and II. Canadian J. Chem. Eng. 43 (1965) $306-313$

18. Al-Tamimi, A. I.; Clark, J. A.: Thermal analysis of a solar collector containing a boiling fluid. Proc. American Solar Energy Society annual meeting, Minneapolis, MN, June 1-3, 1983

19. McNelly, M. J.: A correlation of the rates of heat transfer to nucleate boiling liquids. J. Imp. Coll. Chem. Eng. Soc. 7 (1953) $18-34$

Dr. Ahmed Youssef El-Assy, Assistant Professor Mechanical Engineering Department (Power and Automotive), Faculty of Engineering, Ain Shams University

Abbassia, Cairo, Egypt

Dr. John A. Clark, Professor of Mechanical Engineering Solar Energy Laboratory, Department of Mechanical Engineering and Applied Mechanics, GG Brown Laboratory,

The University of Michigan

Ann Arbor, Michigan 48109-2125, USA

Received October 6, 1986 